$06.1 ; 13.1$

\title{
Особенности токопереноса в пленках поливинилового спирта с включениями многостенных углеродных нанотрубок на подложках Si
}

\author{
(C) C.В. Васин ${ }^{1}$, М.С. Ефримов ${ }^{2}$, В.А. Сергеев ${ }^{1,2}$ \\ ${ }^{1}$ Ульяновский фрилиал Института радиотехники и электроники им. В.А. Котельникова РАН, Ульяновск, Россия \\ 2 Ульяновский государственный технический университет, Ульяновск, Россия \\ E-mail: s.vasin@outlook.com
}

Поступило в Редакцию 6 марта 2020 г.

В окончательной редакции 24 марта 2020 г.

Принято к публикации 24 марта 2020 г.

Показано, что планарные структуры в виде пленок поливинилового спирта (ПВС) с включением многостенных углеродных нанотрубок (МУНТ), нанесенных на кремниевые подложки, и алюминиевыми контактами проявляют выпрямляющие свойства и их вольт-амперные характеристики имеют несимметричный и нелинейный характер. При прямом смещении структуры имеют положительный температурный коэффициент сопротивления (ТКС) в диапазоне температур 270-350 К, тогда как пленочные структуры ПВС без МУНТ проявляют отрицательный ТКС. При обратном смещении у исследованных структур с МУНТ наблюдался ТКС, меняющий знак с отрицательного на положительный. Для объяснения полученных зависимостей рассматривается туннельный механизм токопрохождения.

Ключевые слова: многостенные углеродные нанотрубки, поливиниловый спирт, нанокомпозитные пленочные структуры, электрические свойства.

DOI: 10.21883/PJTF.2020.12.49523.18277

Благодаря своим уникальным свойствам [1] углеродные нанотрубки (УНТ) широко используются в качестве наполнителя для полимеров и, как было неоднократно продемонстрировано [2], могут радикально изменить свойства полимерной матрицы, в которую они включены. Сочетание полимерных органических материалов и УНТ может существенно улучшить свойства исходных полимеров, а также позволяет получить материалы с новыми уникальными механическими, термическими, электрическими или электрохимическими характеристиками.

В настоящей работе исследовалось влияние многостенных углеродных нанотрубок (МУНТ) на изменение электрофизических свойств пленок поливинилового спирта (ПВС). ПВС широко используется в медицине, топливных элементах, оптических волноводных датчиках, датчиках влажности, поляризаторах и голографических решетках, а также в качестве материала диэлектрического слоя в органических тонкопленочных транзисторах [3]. Этот полимер обладает также отличными адгезионными, эмульгирующими и пленкообразующими свойствами, высокой прочностью на растяжение и гибкостью. Все перечисленное выше делает ПВС одним из лучших материалов для полимерной матрицы при создании пленочных нанокомпозитных структур.

Для получения нанокомпозитных пленочных структур на кремниевых подложках использовался доступный на рынке ПВС марки 16/1, а также МУНТ с диаметром 40-80 nm, синтезированные методом MOCVD на разработанной в Ульяновском государственном техническом университете экспериментальной лабораторной установке [4]. Для улучшения совместимости МУНТ с матрицей полимера трубки функционализировали прививкой на поверхности полярных карбоксильных групп $(\mathrm{COOH})$ при обработке сильными кислотами [5].

Первоначально готовился $10 \%$ раствор порошка ПВС в деионизованной воде путем непрерывного перемешивания в магнитной мешалке в течение часа при температуре $90^{\circ} \mathrm{C}$. В полученный раствор методом ультразвукового перемешивания диспергировались МУНТ (1 mass\%). Затем на предварительно очищенные подложки из кремния $n$-типа $(\rho=10 \Omega \cdot \mathrm{cm})$ методом вытягивания из раствора (dip-coating) наносились тонкие пленки композита ПВС + МУНТ и чистого ПВС в качестве контрольных образцов. Скорость вытягивания подложки из раствора выбиралась в диапазоне $1-5 \mathrm{~cm} / \mathrm{min}$. После нанесения пленок структуры подвергались сушке при температуре $80^{\circ} \mathrm{C}$ в течение часа. На поверхность пленок методом термического испарения в вакууме наносились алюминиевые контакты. С обратной стороны кремниевой подложки для обеспечения омического контакта втиралась паста из индий-галлиевой эвтектики. Схематическое изображение полученных таким образом структур показано на вставке к рис. 1, а. Для измерения вольт-амперных характеристик (BAX) использовалась установка на базе программируемого источника питания APS-7313 и двух прецизионных (величина погрешности $<0.015 \%$ ) мультиметров Tektronix DM4040 в режиме измерения напряжения и тока. Напряжение на алюминиевом электроде изменялось с шагом $0.1-0.5 \mathrm{~V}$ с дли- 

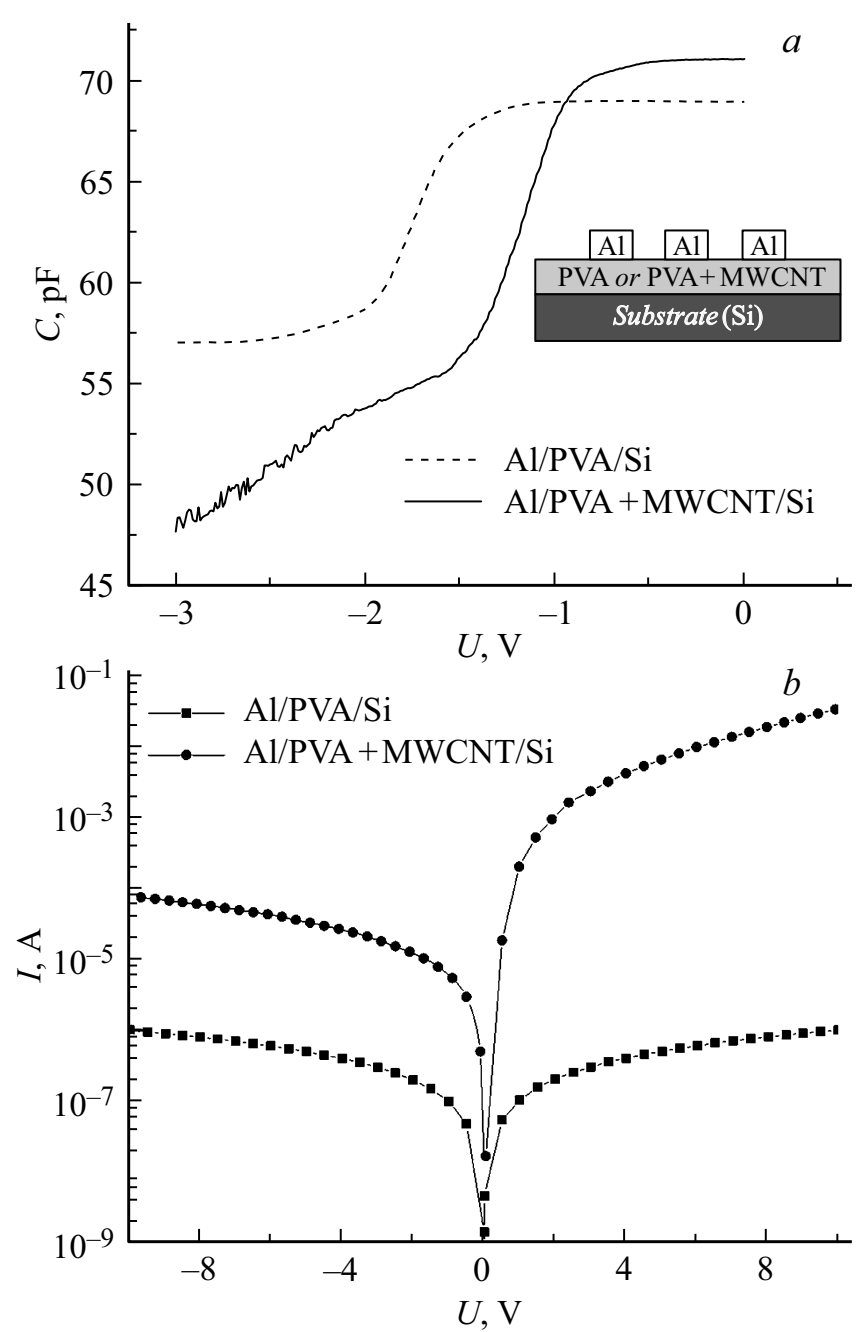

Рис. 1. Вольт-фарадные $(a)$ и вольт-амперные $(b)$ характеристики структур $\mathrm{Al} /$ ПВС/Si и $\mathrm{Al} /$ ПВС + MУНТ/Si при температуре $293 \mathrm{~K}$. На вставке - схематическое изображение исследуемых структур.

тельностью шага $1 \mathrm{~s}$. Как показали эксперименты, этого времени достаточно для установки стабильного значения тока через структуры. Измерения высокочастотных вольт-фарадных характеристик (BФХ) проводились на частоте $100 \mathrm{kHz}$ с помощью LCR-метра Protek 9216A (погрешность $\leq 1 \%$ ). Все измерения выполнялись в термостатированной камере с контролем температуры. Управление процессом измерения осуществлялось с помощью программного комплекса, реализованного в среде LabView. Анализ BAX и ВФХ осуществлялся по общепринятым методикам [6].

На рис. 1, $a$ представлены ВФХ структур $\mathrm{Al} / \mathrm{IBC} / \mathrm{Si}$ и $\mathrm{Al} /$ ПВС $+\mathrm{MУHT/Si}$. ВФХ контрольной структуры $\mathrm{Al} /$ ПВC/Si имеет вид, типичный для МДП-структуры (МДП - металл-диэлектрик-полупроводник). Стандартный анализ такой характеристики [6] позволяет оценить толщину диэлектрической пленки и плотность фиксированного заряда в диэлектрике. Толщина пленки в наших структурах изменялась в диапазоне $500-1000 \mathrm{~nm}$ в зависимости от скорости вытяжки подложки из раствора. Эффективная плотность ловушек заряда составляет величину порядка $10^{9} \mathrm{~cm}^{-2}$, что является хорошим показателем даже для такого традиционного диэлектрика, как $\mathrm{SiO}_{2}$. Добавление в пленку ПВС МУНТ приводит к сдвигу ВФХ в область положительных значений, что свидетельствует о компенсации части положительного заряда при формировании нанокомпозита. В то же время вид зависимости в области отрицательных напряжений смещения становится характерным для режима глубокого обеднения, реализуемого обычно при неравновесном обеднении полупроводника.

BAX контрольных структур $\mathrm{Al} /$ ПВС/Si линейны во всем диапазоне используемых напряжений и имеют довольно малые токи утечки порядка $10^{-6} \mathrm{~A}$, что также свидетельствует о хороших диэлектрических свойствах пленки чистого ПВС. В то же время видно (рис. 1,b), что добавление в ПВС всего лишь 1\% МУНТ приводит к увеличению тока на два порядка при обратном смещении и на четыре порядка при прямом смещении. Кроме того, вольт-амперные характеристики структур $\mathrm{Al} /$ ПВС + MУНТ/Si приобретают ярко выраженный нелинейный характер, что указывает на наличие механизмов токопереноса, характерного для барьерных структур. Однако используемые нами концентрации МУНТ (1\%) слишком малы для включения перколяционного механизма проводимости [7]. Можно предположить, что за механизм переноса тока в данном случае ответственно туннелирование носителей тока между проводящими частицами (в нашем случае МУНТ). В подтверждение этого так же можно трактовать вид ВФХ структур Al/ПВС + MУНT/Si при отрицательных напряжениях смещения. Возросшие токи утечки препятствуют формированию инверсного слоя и приводят к монотонному падению емкости с ростом обратного смещения. Такой вид ВФХ характерен для МДП-структур с туннельно-тонким диэлектриком [8].

На рис. 2 представлены прямые ветви ВАХ структур $\mathrm{Al} /$ ПВС/Si и $\mathrm{Al} /$ ПВС $+\mathrm{MУHT/Si}$, измеренные при различных температурах. Видно, что с ростом температуры структуры $\mathrm{Al} /$ ПВC/Si демонстрируют увеличение тока, в то время как для структур $\mathrm{Al} /$ ПВС $+\mathrm{MУHT/Si}$ характерно противоположное поведение. Иными словами, структуры Al/ПВC/Si имеют отрицательный температурный коэффициент сопротивления, а структуры $\mathrm{Al} /$ ПВС + MУНТ/Si - положительный. На рис. 3, $a$ показаны температурные зависимости тока исследуемых структур при различных напряжениях прямого смещения. Ток в структурах Al/ПВC + MУHT/Si слабо экспоненциально спадает с ростом температуры. В случае обратного смещения (рис. $3, b$ ) зависимость тока от температуры проявляет еще более сложное поведение. Ток растет вплоть до температур $\sim 315 \mathrm{~K}$ и спадает при более высоких температурах.

Подобное поведение также может быть объяснено в рамках модели „прыжкового“ (или туннельного) то- 

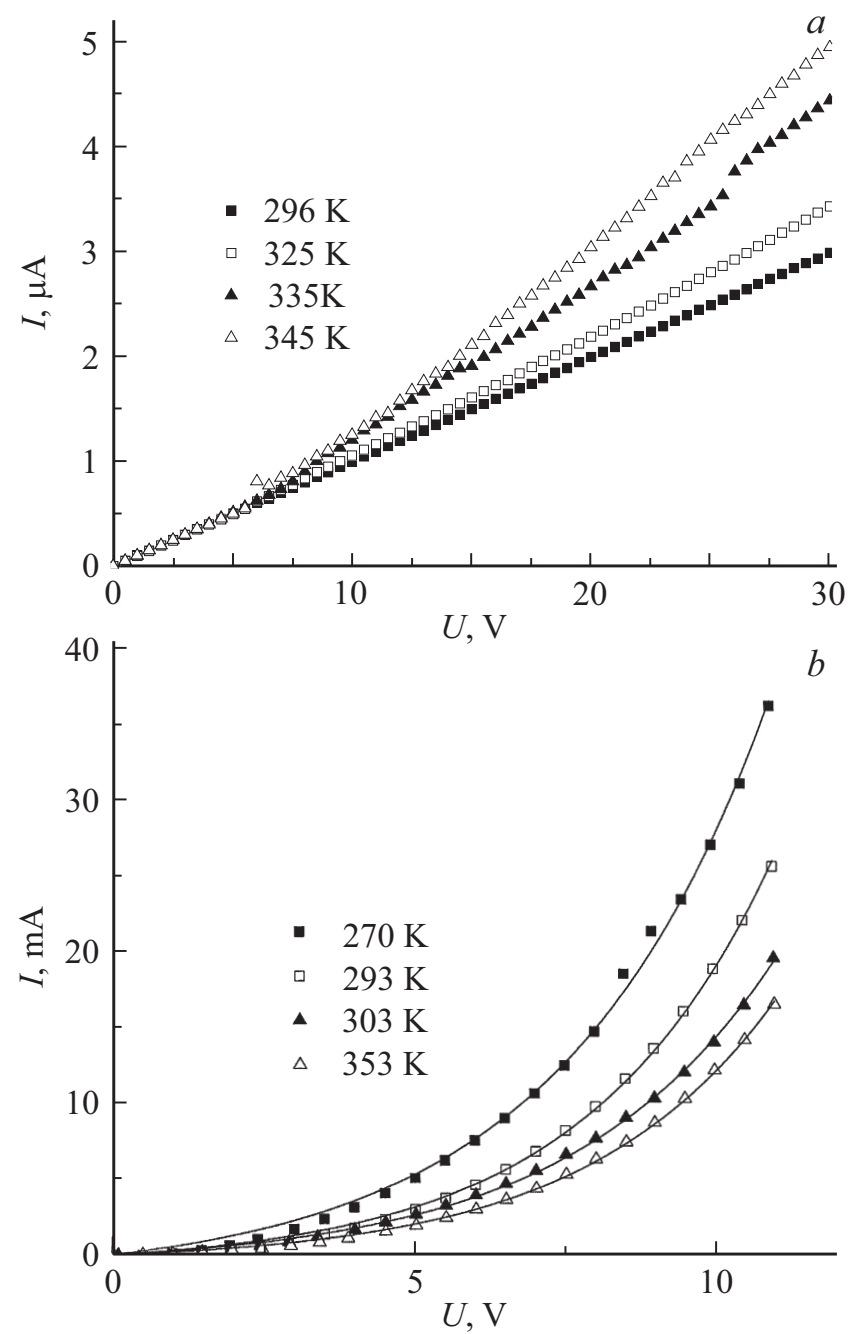

Рис. 2. Вольт-амперные характеристики структур $\mathrm{Al} / \Pi \mathrm{\Pi C} / \mathrm{Si} \quad(a)$ и $\mathrm{Al} / \Pi \mathrm{\Pi C}+\mathrm{MУHT} / \mathrm{Si} \quad(b)$ при прямом смещении, измеренные при различных температурах. Точки - эксперимент, линии на части $b-$ аппроксимация экспоненциальной функцией.

копереноса в композитах с включениями проводящих частиц [9]. Вероятность такого процесса характеризуется всего двумя параметрами: высотой энергетического барьера между частицами $\eta$ и расстоянием между ними $d$ :

$$
T_{N} \simeq \exp \left(-\eta^{1 / 2} d\right) \text {. }
$$

Нагрев пленки ПВС приводит к ее тепловому расширению, а следовательно, увеличиваются и расстояния между МУНТ. Поскольку вероятность туннелирования экспоненциально зависит от расстояния туннелирования, такое расширение приводит к экспоненциальному спаду прямого тока. Однако проведенные нами оценки показали, что учет лишь одного теплового расширения матрицы полимера позволяет добиться согласия с результатами эксперимента при значениях коэффициента линейного теплового расширения $\sim 10^{-4} \mathrm{~K}^{-1}$, что на порядок превышает известные значения для ПВС. Нель- зя также исключать зависимость от температуры высоты энергетического барьера на границе полимер-УНТ. Еще одним фактором, уменьшающим проводимость пленок ПВС + МУНТ с ростом температуры, возможно, является температурная зависимость проводимости самих нанотрубок. Так, в [10] показано, что массивы из отожженных и функционализированных кислотами МУНТ проявляют металлические свойства. В частности, изменение температуры в диапазоне 300-373 K приводит к изменению удельного сопротивления массива МУНТ на 20\%, что также может вносить заметный вклад в наблюдаемые нами зависимости. В случае обратных напряжений смещения увеличение температуры, повидимому, в первую очередь приводит к росту тока за счет механизмов термоэмиссии или термополевой эмиссии, и лишь при более высоких температурах начинают играть роль описанные выше механизмы туннельного переноса и уменьшения удельного сопротивления МУНТ, приводящие к уменьшению обратного тока.
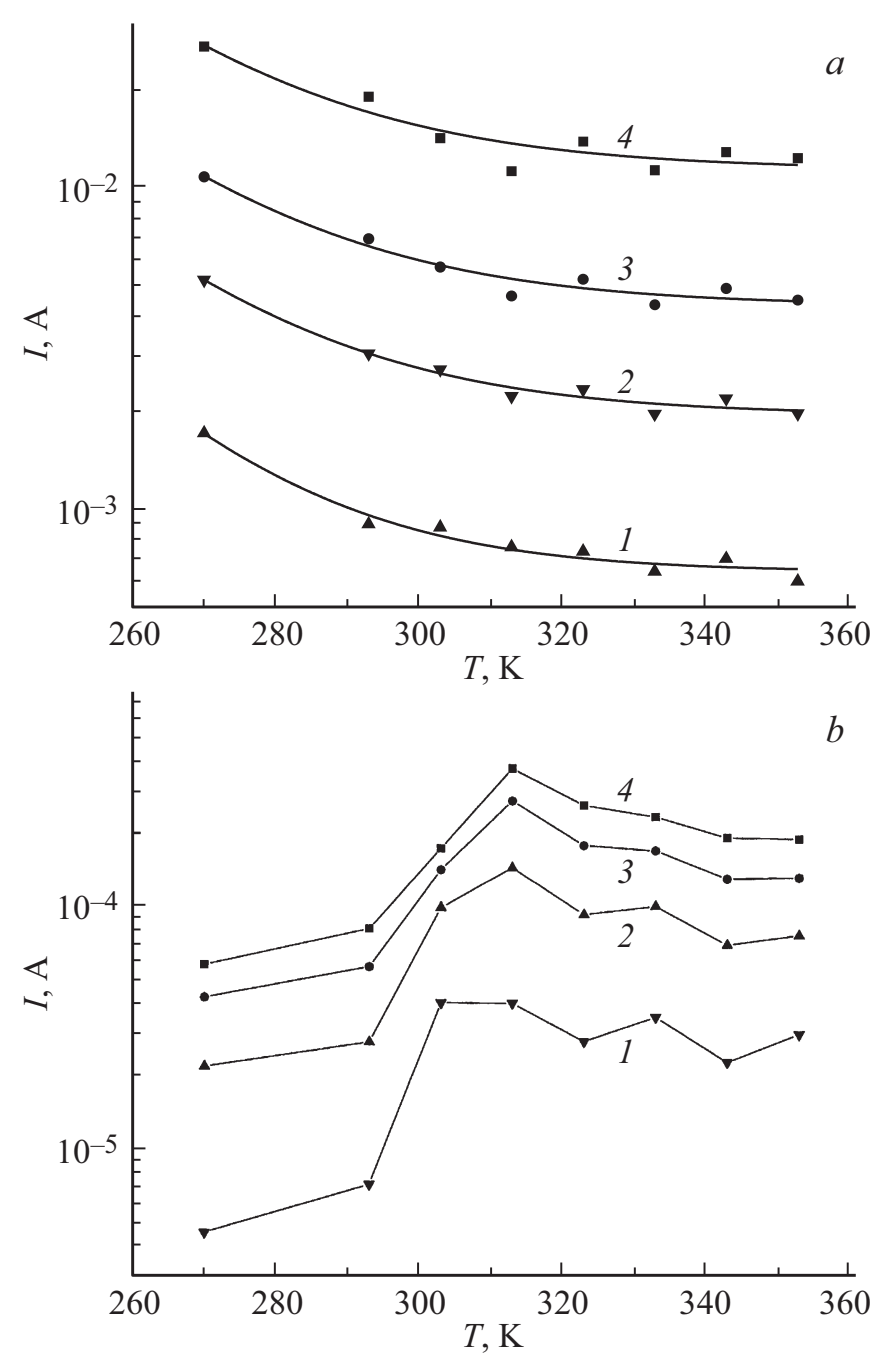

Рис. 3. Зависимости тока $I$ от температуры $T$ при различных напряжениях прямого $(1-3 \mathrm{~V}, 2-5 \mathrm{~V}, 3-7 \mathrm{~V}$, $4-10 \mathrm{~V})(a)$ и обратного $(1-3 \mathrm{~V}, 2-10 \mathrm{~V}, 3-20 \mathrm{~V}$, $4-30 \mathrm{~V})(b)$ смещения для структуры $\mathrm{Al} /$ ПВС + МУНТ/Si. 
Таким образом, на основе результатов проведенных экспериментальных исследований ВАХ и ВФХ пленочных структур ПВС с включением МУНТ на кремниевых подложках установлено, что указанные структуры имеют нелинейный характер вольт-амперных характеристик, положительный температурный коэффициент сопротивления при прямом смещении и меняющий знак с отрицательного на положительный температурный коэффициент сопротивления при обратном смещении.

\section{Финансирование работы}

Работа выполнена в рамках государственного задания при финансовой поддержке Российского фонда фундаментальных исследований и Правительства Ульяновской области (проект № 19-42-730011).

\section{Конфликт интересов}

Авторы заявляют, что у них нет конфликта интересов.

\section{Список литературы}

[1] Сорокин П.Б., Чернозатонский Л.А. // УФН. 2013. Т. 183. № 2. C. 113-132. DOI: 10.3367/UFNr.0183.201302a.0113

[2] Thostenson E.T., Ren Z., Chou T.-W. // Compos. Sci. Technol. 2001. V. 61. N 13. P. 1899-1912.

DOI: $10.1016 / \mathrm{S} 0266-3538(01) 00094-\mathrm{X}$

[3] Facchetti A., Yoon M.-H., Marks T.J. // Adv. Mater. 2005. V. 17. N 14. P. 1705-1725. DOI: 10.1002/adma.200500517

[4] Климов Е.С., Бузаева М.В., Давыдова О.А., Макарова И.А., Светухин В.В., Козлов Д.В., Пиелиниева Е.С., Бунаков Н.А. // ЖПХ. 2014. Т. 87. В. 8. С. 1128-1132.

[5] Климов Е.С., Давыдова О.А., Бузаева М.В., Макарова И.А., Бунаков Н.А., Панов А.А., Пыненков А.А. // Башкир. хим. журн. 2014. Т. 21. № 3. С. 109-113.

[6] 3и С. Физика полупроводниковых приборов. М.: Наука, 1984. $456 \mathrm{c}$.

[7] Chebil A., Doudou B.B., Dridi C., Dammak M. // Mater. Sci. Eng. B. 2019. V. 243. P. $125-130$.

DOI: $10.1016 /$ j.mseb.2019.04.004

[8] Dubey P.K., Filikov V.A., Simmons J.G. // Thin Solid Films. 1976. V. 33. N 1. P. 49-63.

DOI: 10.1016/0040-6090(76)90588-5

[9] Ambrosetti G., Balberg I., Grimaldi C. // Phys. Rev. B. 2010. V. 82. N 13. P. 134201. DOI: 10.1103/PhysRevB.82.134201

[10] Сергеев В.А., Климов Е.С., Фролов И.В. // ЖТФ. 2019. T. 89. B. 8. C. $1223-1228$. 